\title{
Lung cancer mortality in a site producing hard metals
}

Pascal Wild, Alain Perdrix, Sylvie Romazini, Jean-Jacques Moulin, François Pellet

\begin{abstract}
Objectives-To study the mortality from lung cancer from exposures to hard metal dust at an industrial site producing hard metals-pseudoalloys of cobalt and tungsten carbide-and other metallurgical products many of which contain cobalt.

Methods-A historical cohort was set up of all subjects who had worked for at least 3 months on the site since its opening date in the late 1940s. A full job history could be obtained for $95 \%$ of the subjects. The cohort was followed up from January 1968 to December 1992. The exposure was assessed by an industry specific job exposure matrix (JEM) characterising exposure to hard metal dust from 1 to 9 and other possibly carcinogenic exposures as present or absent. Smoking information was obtained by interview of former workers. Standard lifetable methods and Poisson regression were used for the statistical analysis of the data.
\end{abstract}

Results-Mortality from all causes was close to the expected (standardised mortality ratio (SMR) 1.02, 399 deaths) whereas mortality from lung cancer was significantly increased among men (SMR $1.70 ; 46$ deaths, $95 \%$ confidence interval (95\% CI) 1.24 to 2.26 ). By workshop, lung cancer mortality was significantly higher than expected in hard metal production before sintering (SMR 2.42; nine deaths; 95\%CI 1.10 to 4.59 ) and among maintenance workers (SMR 2.56; 11 deaths; 95\%CI 1.28 to 4.59 ), whereas after sintering the SMR was lower (SMR 1.28; five deaths; $95 \%$ CI 0.41 to 2.98 ). The SMR for all exposures to hard metal dust at a level $>1$ in the JEM was in significant excess (SMR 2.02; 26 deaths; 95\%CI 1.32 to 2.96). The risks increased with exposure scores, duration of exposure, and cumulative dose reaching significance for duration of exposure to hard metal dust before sintering, after adjustment for smoking and known or suspected carcinogens.

Conclusion-Excess mortality from lung cancer was found among hard metal production workers which cannot be attributed to smoking alone. This excess occurred mostly in subjects exposed to unsintered hard metal dust.

(Occup Environ Med 2000;57:568-573)

Keywords: lung cancer; hard metals

Recently several studies ${ }^{1-3}$ have found an increased mortality from lung cancer in the hard metal industry. The most recently pub- lished study ${ }^{3}$ was a nested case-control cohort mortality study conducted in all French hard metal production sites. This design was adopted because the full work histories were not available in the records in several companies of this industry and had to be assessed by interview of former staff and colleagues.

The present study describes the mortality of the largest of these production sites which has been in operation since the late 1940s and for which individual job histories existed in the administrative records. A further difference from the other production sites is the simultaneous presence of other industrial processes mostly based on powder metallurgy.

\section{Material and methods}

INDUSTRIAL PROCESSES AND ASSESSMENT OF EXPOSURE

The production of hard metal consists of the following steps: tungsten carbide and cobalt powders (in a proportion ranging between 5\% and $20 \%$ ) are first mixed then granulated. After granulation, raw pieces are obtained by pressing and are shaped by cutting and drilling after presintering. These steps give rise to unsintered hard metal dust that gives simultaneous exposure to cobalt and tungsten carbide before sintering. The pieces are then sintered at a $1300^{\circ} \mathrm{C}$ temperature in a oxygen free furnace and are finally finished by grinding and drilling. This final step gives simultaneous exposure to sintered hard metal dust of cobalt and tungsten carbide.

Other industrial processes include:

- Foundries which produced magnets with cobalt, aluminium and nickel, stellites with cobalt, tungsten, nickel, chromium, and carbon, and stainless steel with iron, cobalt, tungsten, nickel, and chromium

- Production of different pieces of equipment from other sintered alloys of iron, nickel, copper, and tin

- Production of cobalt powders by calcination and reduction of cobalt hydroxide and of tungsten carbide powders starting from the raw Wolframite ore.

Fourteen workshops were thus identified by their production, and regrouped into powder production, hard metal production before sintering, hard metal production after sintering, foundries (three workshops), other sintered alloy production (six workshops), maintenance, and other non-exposed workshops.

An industry specific job exposure matrix was developed for all French factories ${ }^{4}$ by a group of nine experts including three chemical engineers, five physicians, and a statistician. For the present site, it was filled in by a subgroup of this committee consisting of a 
former occupational physician and an engineer from the site and by two medical epidemiologists. The exposures to cobalt, tungsten carbide, and unsintered and sintered hard metal dusts were coded on a scale of $1-9$, along with an indication of exposure frequency $(<10 \%, 10-50 \%,>50 \%)$. Exposures to other substances which have been coded as carcinogenic in some circumstances by the International Agency for Research on Cancer $(\text { IARC) })^{5}$ were coded as present or absent. This list includes asbestos, polycyclic aromatic hydrocarbons, certain chromium compounds, certain nickel compounds, and silica. It must, however, be born in mind that the compounds which have been classified as carcinogens by IARC were not necessarily the compounds to which the cohort members were exposed in this site. All past or present workplaces were thus assessed divided in up to three consecutive periods in which the exposure was considered to be different in level. The exposure was assessed blind to all existing exposure measurements. In the industrywide study, measurements of cobalt (considered to be a tracer for hard metals) showed that concentrations increased in a similar way as in the job exposure matrix, thus validating the expert coding.

Within the foundries and other sintered alloy production workshops, a further four workshops, in which cobalt had been used, were identified.

Exposure to smoking was abstracted from the records of the occupational health department; however, the information was sketchy until 1978, when current smoking or nonsmoking was recorded but no mention was made of past smoking. Therefore this information was reassessed by a volunteer group of former workers.

STUDY POPULATION AND FOLLOW UP

The study population comprised all subjects who had worked at the site for at least 3 months between 1 January 1950, the start of the hard metal production, and 30 June 1992, who were still alive on 1 January 1968. This cohort was abstracted from paper entry registries which were complete since the opening of the site.

For each worker, we gathered information on date and place of birth, date of hire, and end of employment as well as full job histories. Subjects for which the job histories could not be obtained were excluded from the study population. We also could identify all subjects who had died while still employed. We assessed the vital status by writing to the registry offices of the birthplaces and by searching a computerised file of all subjects who had died in France since 1978. Thus foreign born subjects were considered as lost to follow up on the day of leaving employment. We obtained the cause of death by matching the file of dead subjects with the national file of causes of death, which exists since 1968, coded according to the 8th revision of the international classification of diseases $^{6}$ until 1978 and according to the 9th revision $^{7}$ thereafter. As this national file is anonymous, the matching criteria were sex, date of birth, date of death, and place of death.
ANALYTICAL METHODS

We compared the mortality of the cohort with local death rates by standard life table methods. ${ }^{8}$ We accumulated person-years at risk for each worker starting at 3 months of employment or 1 January 1968, whichever came later. Follow up continued until either the date of death, the date of leaving employment for the lost to follow up, 31 December 1992 or the 85th birthday, whichever came first. We obtained standardised mortality ratios (SMRs) by dividing observed number of deaths by age and period standardised expected numbers and we computed exact $95 \%$ confidence intervals (95\% CIs) with the usual Poisson assumption. To account for latency in the analyses by exposure of the lung cancer mortality, all exposures were lagged by 10 years.

Two types of statistical analysis were carried out, based respectively on the workshops in which the subjects worked, and on the exposure classification of the job based on the JEM.

The analysis by workshop was performed for all subjects ever employed in this workshop and for subjects who had only worked in this workshop. For this last analysis, person-years were attributed from (lagged) start of employment in this workshop until end of follow up or any employment in another exposed workshop.

In the analysis by exposures as coded in the job exposure matrix, the exposure to hard metal dust was expressed in different ways: ever exposed, highest exposure score experienced in the work history, duration of exposure at an exposure score $\geqslant 2$, cumulative exposure defined as the sum of score by duration, frequency weighted cumulative exposure in which the score was weighted by the frequency code (by 0.05 for $<10 \%, 0.3$ for $10 \%-50 \%$, 0.75 for $>50 \%$ ). Duration of exposure was recoded into non-exposed, exposed $<10$ years, 10-20 years, and $>20$ years. Both cumulative exposure scores were recoded into four categories, in each of which the expected number of deaths from lung cancer was equal to the quarter of the total number in the cohort. At any time the person-time was allocated to the relevant category on a day to day basis. To test for an internal trend with increasing exposure, the ranks of the exposure scores were fitted in a Poisson regression model that included smoking categories defined as non-smoker, ever smoker, and unknown smoking category, and any exposure to the IARC carcinogens coded in the JEM. To account for effects of age and period, we included expected numbers as offsets. We used the person-years program to compute the SMRs ${ }^{9}$ and we reproduced these computations with a series of STATA routines ${ }^{10}$ thus allowing a flexible fit of Poisson models within STATA. ${ }^{11}$

\section{Results}

OVERALL DESCRIPTIONS

The initial cohort comprised 3398 subjects. Of these, 19 had left employment before 1950, nine subjects worked $<3$ months. Moreover 79 subjects had died before 1968, and 296 
Table 1 Description of the study population

\begin{tabular}{|c|c|c|c|c|}
\hline & \multicolumn{2}{|l|}{ Men } & \multicolumn{2}{|l|}{ Women } \\
\hline & $n$ & $(\%)$ & $n$ & $(\%)$ \\
\hline \multicolumn{5}{|l|}{ Subjects (n): } \\
\hline Included & 2216 & 95 & 644 & 97 \\
\hline Excluded & 112 & 5 & 23 & 3 \\
\hline Lost to follow up & 590 & & 135 & \\
\hline Person-years & 40542 & & 11960 & \\
\hline \multicolumn{5}{|l|}{ Deaths (n): } \\
\hline All causes & 331 & & 68 & \\
\hline Lung cancer & 46 & & 1 & \\
\hline \multicolumn{5}{|l|}{ Date employed: } \\
\hline$<1950$ & 76 & 3 & 15 & 2 \\
\hline $1950-9$ & 912 & 41 & 157 & 24 \\
\hline $1960-9$ & 816 & 37 & 309 & 48 \\
\hline $1970-9$ & 353 & 16 & 139 & 22 \\
\hline$\geqslant 1980$ & 59 & 3 & 24 & 4 \\
\hline Smoking (\%) & Total & Lung cancer & Total & Lung cancer \\
\hline Never & 20 & 15 & 87 & 100 \\
\hline Current or former & 48 & 63 & 12 & - \\
\hline Unknown` & 32 & 22 & 2 & - \\
\hline
\end{tabular}

*Includes subjects classified as non-smoker or former smoker.

subjects who were born abroad left before 1968 and were thus censored from the cohort before the beginning of the follow up. Among the remaining 2993 subjects, 133 with incomplete or missing work histories were excluded. The final number of subjects meeting the inclusion criteria was thus 2860 (2216 men, table 1). Most of the subjects $(80 \%)$ were hired before 1970 and mean follow up was 18.6 years. Overall smoking is close to a population survey conducted in $1980-1,{ }^{12}$ in which the total number of smokers was equal to $46 \%$ among men and $16 \%$ among women (data not shown). A very weak association was found between exposure and smoking, $57 \%$ of smokers among subjects exposed to sintered hard metals versus $51 \%$ non-exposed, for unsintered hard metal the figures are $54 \%$ versus $52 \%$. The death certificates could be found for 350 subjects and 32 further causes were obtained from local doctors. Thus $96 \%$ of the causes could be retrieved, among which were 47 deaths from lung cancer. Table 2 gives the overall mortality pattern compared with the local death rates: apart from the excess from lung cancer, no cause seemed to be in significant excess, the mortality from all causes being close to the expected value.

ACCORDING TO WORKSHOP

The description of mortality from lung cancer by workshop (table 3) confirms that within the workshops called non-exposed which consisted of all except the production and the maintenance workshops, the observed number of lung cancers was close to the expected (SMR 0.95). Non-exposure is not strictly true as the JEM assigns a low frequency and low level (score 2) exposure to hard metal dust to some jobs within the laboratories.

In hard metal production, without the distinction of sintered or not, we found an SMR of 1.93 based on 14 cases (95\% CI 1.05 to 3.23). Consistently high SMRs were found (SMR 2.42, nine cases for ever employed, SMR 2.91, six cases for employed only in these workshops) for subjects who had worked in hard metal production steps before sintering, whereas in the workshops after sintering, only a small excess was found (SMR 1.28, five cases for ever employed, SMR 1.13, three cases for employed only in these workshops).

Non-significant increases of mortality from lung cancer were reported in the three foundry workshops (SMR 1.89, 11 cases for ever employed, SMR 1.8, six cases for employed only in these workshops) and in the six production workshops of sintered alloys other than hard metals (SMR 1.29, six cases for ever employed, SMR 1.75, five cases for employed only in these workshops). Although no exposure to hard metal dust has been coded for these workshops, some jobs in these workshops have been attributed to exposures to asbestos, polycyclic aromatic hydrocarbons, nickel, chromium, and cobalt. The analyses by the smaller workshops did not show any isolated risk. In the powder production workshops also, we found SMRs >1 (SMR 1.92, five cases for ever employed, SMR 1.39, two cases for employed only in maintenance), although the number of subjects who had worked only in these

Table 2 Mortality for selected causes (2216 men and 644 women)

\begin{tabular}{|c|c|c|c|c|c|c|c|c|}
\hline & \multicolumn{4}{|l|}{ Men } & \multicolumn{4}{|l|}{ Women } \\
\hline & Observed & Expected & $S M R$ & $95 \% C I$ & Observed & Expected & $S M R$ & $95 \% C I$ \\
\hline All causes & 331 & 336.49 & 0.98 & 0.88 to 1.10 & 68 & 53.80 & 1.26 & 0.98 to 1.60 \\
\hline Circulatory system & 79 & 86.60 & 0.91 & 0.72 to 1.14 & 19 & 15.25 & 1.25 & 0.75 to 1.95 \\
\hline Ischaemic heart diseases & 34 & 35.39 & 0.96 & 0.67 to 1.34 & 6 & 3.89 & 1.54 & 0.56 to 3.36 \\
\hline Respiratory system & 11 & 15.53 & 0.71 & 0.35 to 1.27 & 3 & 2.39 & 1.26 & 0.25 to 3.67 \\
\hline Chronic bronchitis or emphysema & 0 & 2.67 & 0.00 & 0.00 to 1.37 & 1 & 0.24 & 4.25 & 0.11 to 23.7 \\
\hline Pneumoconiosis & 1 & 0.55 & 1.82 & 0.02 to 10.1 & 0 & 0.01 & 0.00 & 0.00 to 367 \\
\hline Fibrosis & 0 & 0.27 & 0.00 & 0.00 to 13.6 & 0 & 0.04 & 0.00 & 0.00 to 88.5 \\
\hline All cancer sites & 118 & 109.05 & 1.08 & 0.90 to 1.30 & 22 & 17.49 & 1.26 & 0.79 to 1.90 \\
\hline Oral cavity or pharynx & 14 & 9.15 & 1.53 & 0.84 to 2.57 & 1 & 0.22 & 4.57 & 0.12 to 25.5 \\
\hline Larynx & 3 & 6.18 & 0.49 & 0.10 to 1.42 & 0 & 0.07 & 0.00 & 0.00 to 51.9 \\
\hline Oesophagus & 9 & 6.66 & 1.35 & 0.62 to 2.57 & 0 & 0.15 & 0.00 & 0.00 to 24.5 \\
\hline Stomach & 1 & 5.80 & 0.17 & 0.00 to 0.96 & 1 & 0.80 & 1.26 & 0.03 to 7.00 \\
\hline Intestine & 3 & 6.50 & 0.46 & 0.09 to 1.35 & 1 & 1.46 & 0.68 & 0.02 to 3.81 \\
\hline Rectum & 1 & 3.09 & 0.32 & 0.01 to 1.80 & 2 & 0.56 & 3.54 & 0.43 to 12.8 \\
\hline Liver & 5 & 4.90 & 1.02 & 0.33 to 2.38 & 0 & 0.29 & 0.00 & 0.00 to 12.6 \\
\hline Pancreas & 5 & 4.43 & 1.13 & 0.36 to 2.63 & 1 & 0.66 & 1.52 & 0.02 to 8.43 \\
\hline Lung & 46 & 27.11 & 1.70 & 1.24 to 2.26 & 1 & 0.84 & 1.19 & 0.02 to 6.62 \\
\hline Breast & & & & & 6 & 4.20 & 1.43 & 0.52 to 3.11 \\
\hline Pleura & 2 & 0.82 & 2.44 & 0.27 to 8.81 & 0 & 0.07 & 0.00 & 0.00 to 51.0 \\
\hline Bladder & 2 & 3.02 & 0.66 & 0.07 to 2.39 & 0 & 0.19 & 0.00 & 0.00 to 19.7 \\
\hline Brain & 0 & 2.05 & 0.00 & 0.00 to 1.79 & 0 & 0.44 & 0.00 & 0.00 to 8.34 \\
\hline Hodgkin's disease and lymphoma & 1 & 3.44 & 0.29 & 0.01 to 1.62 & 1 & 0.77 & 1.30 & 0.02 to 7.23 \\
\hline Leukaemia & 0 & 3.32 & 0.00 & 0.00 to 1.10 & 1 & 0.70 & 1.43 & 0.02 to 7.95 \\
\hline
\end{tabular}


Table 3 Lung cancer according to workshops among men

\begin{tabular}{lllll}
\hline & Observed & Expected & SMR & 95\% CI \\
\hline Only employed ${ }^{\star}$ in: & & & & \\
$\quad$ Non-exposed workshops & 7 & 7.40 & 0.95 & 0.38 to 1.95 \\
Hard metal production before sintering & 6 & 2.06 & 2.91 & 1.06 to 6.34 \\
Hard metal production after sintering & 3 & 2.66 & 1.13 & 0.31 to 2.89 \\
Other sintered alloy production & 5 & 2.85 & 1.75 & 0.57 to 4.09 \\
Foundries & 6 & 3.34 & 1.80 & 0.66 to 3.91 \\
Maintenance & 9 & 3.19 & 2.82 & 1.29 to 5.36 \\
Powder production & 2 & 1.44 & 1.39 & 0.17 to 5.02 \\
Ever employed in & & & & \\
$\quad$ Hard metal production before sintering & 9 & 3.72 & 2.42 & 1.10 to 4.59 \\
Hard metal production after sintering & 5 & 3.91 & 1.28 & 0.41 to 2.98 \\
Other sintered alloys production & 6 & 4.66 & 1.29 & 0.47 to 2.80 \\
$\quad$ Foundries & 11 & 5.82 & 1.89 & 0.94 to 3.38 \\
Maintenance & 11 & 4.29 & 2.56 & 1.28 to 4.59 \\
Powder production & 5 & 2.60 & 1.92 & 0.62 to 4.49 \\
\hline With & & & &
\end{tabular}

*With the exclusion of employment in any other exposed workshop.

†All workshops except the workshops listed.

Table 4 Lung cancer by other occupational exposures according to the job exposure matrix and by smoking, among men

\begin{tabular}{|c|c|c|c|c|}
\hline & Observed & Expected & $S M R$ & $95 \% C I$ \\
\hline \multicolumn{5}{|c|}{ Exposures coded in the job exposure matrix other than hard metal: } \\
\hline Asbestos & 13 & 6.67 & 1.95 & 1.04 to 3.33 \\
\hline $\mathrm{PAH}^{\star}$ & 13 & 6.54 & 1.99 & 1.06 to 3.40 \\
\hline Silica & 9 & 5.20 & 1.73 & 0.79 to 3.29 \\
\hline Nickel compounds & 15 & 8.51 & 1.76 & 0.99 to 2.91 \\
\hline Chromium compounds & 2 & 0.96 & 2.08 & 0.23 to 7.52 \\
\hline Cobalt except in hard metals & 15 & 7.68 & 1.95 & 1.09 to 3.22 \\
\hline Any IARC carcinogen $\dagger$ & 26 & 12.71 & 2.05 & 1.34 to 3.00 \\
\hline \multicolumn{5}{|l|}{ Smoking: } \\
\hline Non-smokers & 7 & 5.17 & 1.35 & 0.54 to 2.79 \\
\hline Ever smokers & 29 & 12.84 & 2.26 & 1.51 to 3.24 \\
\hline Unknown smoking status $\ddagger$ & 10 & 9.09 & 1.10 & 0.53 to 2.02 \\
\hline
\end{tabular}

^Polycyclic aromatic hydrocarbons.

†Asbestos, PAH, silica, nickel, and chromium compounds.

$\ddagger$ Including subjects coded as former smoker or non-smoker.

Table 5 Lung cancer by exposure to hard metal dusts * according to the job exposure matrix among men

\begin{tabular}{|c|c|c|c|c|c|}
\hline & Observed & Expected & $S M R$ & $95 \% C I$ & $\begin{array}{l}\text { Test for } \\
\text { trend } \neq \\
\text { p value }\end{array}$ \\
\hline \multicolumn{5}{|c|}{ By highest exposure score in the job history: } & \multirow[t]{6}{*}{0.17} \\
\hline $0-1$ & 20 & 14.23 & 1.41 & 0.86 to 2.17 & \\
\hline $2-3$ & 7 & 3.33 & 2.10 & 0.84 to 4.33 & \\
\hline $4-5$ & 15 & 8.13 & 1.85 & 1.03 to 3.04 & \\
\hline$\geqslant 6$ & 4 & 1.43 & 2.80 & 0.76 to 7.16 & \\
\hline$\geqslant 2$ & 26 & 12.89 & 2.02 & 1.32 to 2.96 & \\
\hline \multicolumn{5}{|c|}{ By duration at a score $\geqslant 2 \mathrm{y}$ : } & \multirow[t]{5}{*}{0.07} \\
\hline Non-exposed & 20 & 14.23 & 1.41 & 0.86 to 2.17 & \\
\hline$<10$ & 11 & 7.01 & 1.57 & 0.78 to 2.81 & \\
\hline $10-19$ & 10 & 3.99 & 2.51 & 1.20 to 4.61 & \\
\hline$\geqslant 20$ & 5 & 1.89 & 2.65 & 0.85 to 6.17 & \\
\hline \multicolumn{5}{|c|}{ By increasing unweighted cumulative doses: } & \multirow[t]{5}{*}{0.23} \\
\hline Dose 1 & 8 & 6.86 & 1.17 & 0.50 to 2.30 & \\
\hline Dose 2 & 11 & 6.62 & 1.66 & 0.83 to 2.97 & \\
\hline Dose 3 & 11 & 6.84 & 1.61 & 0.80 to 2.88 & \\
\hline Dose 4 & 16 & 6.79 & 2.36 & 1.35 to 3.83 & \\
\hline \multicolumn{5}{|c|}{ By increasing frequency weighted cumulative doses: } & \multirow[t]{5}{*}{0.37} \\
\hline Dose 1 & 9 & 6.75 & 1.33 & 0.61 to 2.53 & \\
\hline Dose 2 & 11 & 6.81 & 1.62 & 0.81 to 2.89 & \\
\hline Dose 3 & 12 & 6.76 & 1.78 & 0.92 to 3.10 & \\
\hline Dose 4 & 14 & 6.78 & 2.06 & 1.13 to 3.46 & \\
\hline
\end{tabular}

${ }^{\star}$ Consisting of simultaneous exposure to cobalt and tungsten carbide.

†Within a Poisson regression model adjusted for smoking and IARC carcinogens.

workshops was small (the expected number of lung cancers was 1.44).

Finally significantly increased SMRs were found in the maintenance workshop (SMR $2.56,95 \%$ CI 1.28 to 4.59 ). As the maintenance work was not specific to any industrial process, high exposure scores to hard metal dusts were coded in the JEM for most maintenance jobs, although with a low frequency. This was the case for 10 of the 11 cases of lung cancer.
ACCORDING TO THE JOB EXPOSURE MATRIX

In table 4, we assessed the effect of possible confounders on mortality from lung cancer. All exposures to IARC carcinogens were associated with high SMRs. However, none of these exposures existed alone, so that we created a summary exposure index indicating the exposure to any of the IARC carcinogens. Twenty six out of 46 deaths from lung cancer worked in jobs in which such an exposure has been assessed in the JEM (SMR 2.05, 95\% CI 1.34 to 3.00). For smoking, a high SMR for smokers was expected, but an SMR >1 (SMR 1.35, seven cases) among non-smokers was also found.

This larger than expected mortality among non-smokers could be at least partially due to an occupational exposure as four out of the seven non-smoking cases were exposed to hard metal dusts (SMR 1.48 among non-smokers exposed to hard metal dust versus $\mathrm{SMR}=1.21$ among non-smokers not exposed to hard metal dust) and the three others were exposed to IARC carcinogens. Among non-smokers exposed neither to hard metal dust nor to any of the IARC carcinogens no case was found versus 1.27 expected.

Table 5 gives the detail of the analyses by exposure to hard metal dust whether sintered or not. For all subjects exposed at a level $>1$, a significantly increased SMR was found based on 26 cases (SMR 2.02, 95\% CI 1.32 to 2.96). The SMRs increased from 1.41 (score 0 or 1 ) to 2.80 (score $>5$ ) for the highest score in the work history, from 1.41 (non-exposed) to 2.65 for $>20$ years of exposure at a score at $\geqslant 2$, from 1.17 to 2.36 by quartiles of unweighted cumulative scores and from 1.33 to 2.06 by quartiles of frequency weighted cumulative scores. However, none of these trends was significant in the Poisson regression model. Nevertheless, the highest exposure categories corresponded consistently to the highest SMRs.

Table 6 cross tabulates exposure to IARC carcinogens, exposure to sintered hard metal dust and duration of exposure to unsintered hard metal dust and presents the Poisson regression model with these three exposures and smoking categories. This model identifies an increased relative risk associated with IARC carcinogens, and a significantly increasing trend with duration of exposure to unsintered hard metal dust. However, exposure to sintered hard metal dust was associated with a relative risk $<1$. The results of the analyses with the other exposure scores (highest exposure score or cumulative exposure scores) were similar to the result by duration of exposure but none of them reached significance.

\section{Discussion}

\section{EXPOSURE ASSESSMENT}

Although this study was focused on risks associated with hard metal production, it must be stressed that several other simultaneous productions existed in this industrial site in which several potential carcinogens were assessed by the expert group. The validity of the JEM is certainly good within hard metal production, but given that the focus was not on the other 
Table 6 Lung cancer by duration of exposure to unsintered hard metal dust, ${ }^{1}$ exposure to sintered hard metal dust $t^{2}$ and IARC carcinogens according to the job exposure matrix among males

\begin{tabular}{|c|c|c|c|c|c|c|}
\hline Unsintered & Sintered & Observed & Expected & $S M R$ & \multicolumn{2}{|l|}{$95 \% C I$} \\
\hline \multicolumn{7}{|c|}{ Not exposed to any IARC carcinogen: } \\
\hline Non-exposed & Non-exposed & 7 & 6.13 & 1.14 & 0.46 to & 2.35 \\
\hline$<10 y$ & Non-exposed & 2 & 0.97 & 2.06 & 0.25 to & 7.45 \\
\hline $10-19 y$ & Non-exposed & 2 & 0.53 & 3.77 & 0.46 to 1 & 13.63 \\
\hline$\geqslant 20 y$ & Non-exposed & 1 & 0.25 & 4.00 & 0.10 to 2 & 22.29 \\
\hline Total exposed & Non-exposed & 5 & 1.75 & 2.86 & 0.92 to & 6.67 \\
\hline Non-exposed & Exposed & 3 & 2.64 & 1.14 & 0.23 to & 3.32 \\
\hline$<10 y$ & Exposed & 1 & 1.83 & 0.55 & 0.01 to & 3.04 \\
\hline $10-19 y$ & Exposed & 2 & 1.19 & 1.68 & 0.20 to & 6.07 \\
\hline$\geqslant 20 y$ & Exposed & 2 & 0.87 & 2.30 & 0.28 to & 8.30 \\
\hline Total exposed & Exposed & 5 & 3.89 & 1.29 & 0.41 to & 3.00 \\
\hline \multicolumn{7}{|c|}{ Exposed to any IARC carcinogen: } \\
\hline Non-exposed & Non-exposed & 13 & 8.10 & 1.60 & 0.85 to & 2.74 \\
\hline$<10 y$ & Non-exposed & 2 & 1.00 & 2.00 & 0.24 to & 7.22 \\
\hline $10-19 y$ & Non-exposed & 2 & 0.19 & 10.53 & 1.27 to 3 & 38.02 \\
\hline$\geqslant 20 \mathrm{y}$ & Non-exposed & 0 & 0.06 & 0.00 & 0.00 to & 61.13 \\
\hline Total exposed & Non-exposed & 4 & 1.25 & 3.20 & 0.87 to & 8.19 \\
\hline Non-exposed & Exposed & 1 & 0.46 & 2.17 & 0.05 to & 12.11 \\
\hline$<10 \mathrm{y}$ & Exposed & 4 & 1.58 & 2.53 & 0.69 to & 6.48 \\
\hline $10-19 y$ & Exposed & 3 & 0.95 & 3.16 & 0.65 to & 9.23 \\
\hline$\geqslant 20 \mathrm{y}$ & Exposed & 1 & 0.37 & 2.70 & 0.07 to & 15.06 \\
\hline Total exposed & Exposed & 8 & 2.90 & 2.76 & 1.19 to & 5.44 \\
\hline \multicolumn{4}{|c|}{ Poisson regression } & $R R$ & $95 \% C I$ & \\
\hline \multicolumn{4}{|c|}{ Ever smoker $v$ non-smoker } & 1.58 & 0.69 to & 3.63 \\
\hline \multicolumn{4}{|c|}{ Unknown $v$ non-smoker } & 0.86 & 0.32 to & 2.25 \\
\hline \multicolumn{4}{|c|}{ Exposure to any IARC carcinogen $\ddagger$ (yes $v$ no) } & 1.48 & 0.81 to & 2.68 \\
\hline \multicolumn{4}{|c|}{ Exposure to sintered hard metal dust (yes $v$ no) } & 0.75 & 0.37 to & 1.53 \\
\hline \multicolumn{4}{|c|}{ By recoded duration of exposure to unsintered hard metal dust $\$$} & 1.43 & 1.03 to & 1.98 \\
\hline
\end{tabular}

${ }^{\star}$ Consisting of simultaneous exposure to cobalt and tungsten carbide before sintering.

†Consisting of simultaneous exposure to cobalt and tungsten carbide after sintering.

†Asbestos, PAH, silica, nickel, chromium compounds.

\Non-exposed $=1 ;<10 \mathrm{y}=2 ; 10-20 \mathrm{y}=3 ;>20 \mathrm{y}=4$.

processes, the exposures within these other workshops were assessed in less detail or were not very precise, as in the maintenance workshop, which was not specifically hard metal production. This is especially a problem in the case of subjects who had worked in the maintenance workshop without a more accurate description of their actual job. It is therefore possible that their classification as exposed or not to any IARC carcinogen, which was used as a proxy for the exposures in the other workshops, leaves room for some misclassification.

Fortunately, in this industrial site, the turnover in jobs was low, most of the cohort members and the cases of lung cancer had only had one job in their entire work history, so that with the exception of maintenance workers, the hard metal exposures were not confounded with exposures from the other industrial processes. Moreover, a large exposure gradient for hard metal dust existed in the cohort, with high exposures in the hard metal production, minor and low frequency exposures in laboratories, and higher but low frequency exposures to hard metal dust (sintered or unsintered) among maintenance workers.

DATA COLLECTION AND FOLLOW UP

Although the initial population from which the present cohort was abstracted was larger, the French system for tracing causes of death had not allowed for earlier systematic tracing. The present cohort definition was therefore the most extensive possible. This definition resulted in the exclusion of several early workers who might have been heavily exposed, and overall, the risk might have been higher, had it been possible to trace all causes of death. From the cohort that met the definition, about $5 \%$ of the population was excluded from the analysis, due to missing job histories, among which were two lung cancer deaths versus 2.56 expected. As these missing work histories occurred mostly among short term workers, for which no records had been kept, they were unlikely to alter the observed trends to any extent. In the same way, the main analyses were carried out among men only. We considered that the added information coming from the women (one lung cancer death versus 0.84 expected) did not compensate for the added heterogeneity. Due to difficulties in tracing the vital status and causes of death, we censored all foreign born subjects as soon as they left the factory, so that for this subpopulation, we investigated the mortality only while employed. However, despite the large number $(21 \%$ of the male population) of subjects thus lost to follow up, this should not create any major bias if a small possible bias is accepted towards absence of risk caused by the healthy worker effect which is usually stronger among active than among retired workers. ${ }^{13}$ As mentioned earlier, the smoking information from the medical records could not be used directly and had to be assessed from former colleagues. This procedure may have resulted in some misclassification; however, the higher than expected mortality from lung cancer among non-smokers based on seven cases remains intriguing. Had these cases been long term or heavy smokers, they would not have been classified as nonsmokers by their former colleagues. In any case, it is unlikely that exposed cases who smoked are misclassified as non-smokers more often than are non-exposed cases.

LUNG CANCER AND EXPOSURE TO HARD METAL DUST

The experimental evidence for hard metal particles containing cobalt and tungsten carbide to cause toxicity of the lung has been discussed in detail by Moulin et al. ${ }^{3}$ The suggested mechanism relies on DNA damage caused by activated oxygen species. ${ }^{14}$ However, the main evidence for a carcinogenic effect of hard metal dust comes from one Swedish and two French papers in which lung cancer was in significant excess.

The present study population is included in the nationwide population studied by Moulin et $a l^{3}$ although after a further year four new deaths from lung cancer occurred. It comes, therefore, as no surprise that the internal regressions, based on the JEM, give results very close to the larger study and confirm the doseresponse relations between exposures to hard metal and risks of lung cancer found in the previous study.

Although the present study has its own strengths because for every member a full job history was available so that we could compare the mortality from lung cancer in individual workshops with the local death rates, the study by Moulin et $a l^{3}$ relied only on internal comparisons in a nested case-control study based on the JEM. This is all the more important as increased SMRs were found not only in some other production workshops present in 
this industrial site (foundries and other sites that produced sintered alloys), but also in the maintenance workshop. These increased risks are difficult to interpret as several possibly carcinogenic exposures had been coded by the experts who developed the JEM.

A potential problem with these excesses in lung cancer in other workshops, is that they could lead to biases in the estimation of risk due to hard metal dust in the internal regression. Therefore, the analyses based on the workshops solely, which are independent of the JEM and which show significantly increased SMRs in the hard metal production workshops, provide an important confirmation of the carcinogenic risk from hard metal dust found in the nationwide case-control study. ${ }^{3}$ This suggests that whatever exposure misclassification may exist in the JEM, it did not produce false positive results. In particular the high exposure ratings in the maintenance workshop did not create the dose-response relation found. On the other hand this suggests also that the overall excess in lung cancer (SMR 1.70 based on 46 cases) is not entirely attributable to exposures to hard metal dust. There is no evidence that the maintenance workers are any different from the rest of the population in their duration of employment or their smoking behaviour; their increased risk might be due to a combined exposure to hard metal dust and exposure to asbestos, which was coded by the experts in this workshop.

A final point, which was not as clear in the nationwide study, but which may have public health consequences, is the tentative evidence that the risk of lung cancer is restricted to unsintered hard metal dust. This evidence is based on the fact that for subjects exposed to unsintered hard metal dust, the risk is clear: for subjects who had worked only in the hard metal production workshop before sintering, the SMR was significantly increased (SMR 2.91 based on six cases), and the relative risks increase significantly with duration of exposure to unsintered hard metal dust. On the other hand, for subjects who had worked only in the hard metal production workshop after sintering, the SMR is close to one (SMR 1.13 based on three cases), and the internal relative risk estimate is $<1$ (RR 0.75). It must, however, be noted that the highest exposures certainly occurred in the processes before sinteringthat is, in the powder mixing step or in the tooling before sintering. Only in these steps did the experts assign exposure levels $>5$ (maximum 9) in the JEM. It is therefore possible that the range in exposure after sintering is too small to detect an association if there is one. Moreover, no initial biological knowledge that we are aware of explains this absence of risk for exposure to sintered hard metal dust. No final conclusion about the absence of carcinogenicity of sintered hard metal dust can therefore be reached from this study.

SMOKING AND EXPOSURE

In the industrywide study, ${ }^{3}$ there was some suggestive evidence of a positive interaction between smoking and exposure to hard metal dust. This is not confirmed in the present study, as a larger than expected SMR was found among non-smokers. Either this is due to some smoking misclassification, in this case any discussion on interaction is useless, or this high SMR is caused by an occupational exposure. As no case of lung cancer was found among the non-exposed men, this explanation is consistent with the data. The use of an unknown smoking category in the Poisson regression was not optimal. ${ }^{15}$ However, as smoking was not the main focus of the analysis, we considered that it was preferable to complete the case analysis and a more complex modelling procedure was not justified.

\section{Conclusion}

An excess mortality from lung cancer was found among workers producing hard metals which cannot be attributed to smoking alone. This excess appeared mostly in subjects exposed to unsintered hard metal dust.

1 Hogstedt C, Alexandersson R. Mortality among hard-metal workers. Arbete Hälsa 1990;21:1-26.

2 Lasfargues G, Wild P, Moulin JJ, et al. Lung cancer mortality in a French cohort of hard-metal workers. $A m \mathcal{F}$ Ind Med 1994;26:585-95.

3 Moulin JJ, Wild P, Romazini S, et al. Lung cancer risk in hard-metal workers. Am f Epidemiol 1998;148:241-8.

4 Moulin JJ, Romazini, Lasfargues G, et al. Elaboration d'une matrice emplois-expositions dans l'industrie productrice de métaux durs en France (in French). Rev Epidem Santé Publ 1997;45:41-51.

5 Lists of IARC evaluations. IARC Monogr Eval Carcinog Risks Hum 1997;69:1-631.

6 World Health Organization. Manual of the international classification of diseases, injuries and causes of death, 8th revision. Geneva, Switzerland :WHO 1968.

7 World Health Organization. Manual of the international classification of diseases, injuries and causes of death, 9th classification of diseases, injuries and causes
revision. Geneva, Switzerland :WHO 1978.

8 Breslow NE, Day NE. Statistical methods in cancer research. Vol II. The design and analysis of cohort studies. Lyon: International Agency for Research on Cancer, 1987. (Sci Publ No 82.)

9 Coleman M, Douglas A, Hermon C, et al. Cohort study analysis with a Fortran computer program. Int $\mathcal{f}$ Epidemiol 1986;15:134-7

10 Clayton DG, Hills M. Analysis of follow-up studies with Stata 5.0. Stata Technical Bulletin 1997;40:17-19.

11 StatCorp. Stata statistical software: Release 5.0. College Stattion, TX: Stata Corporation, 1997.

12 SESI. Les consommateurs de boissons alcooliques et de tabac. Enquête sur la santé et les soins médicaux 1980-1. Paris: Solidarité Santé, Cahiers Statistiques, Ministère des Affaires Sociales et de la Solidarité Nationale, 1984.

13 Steenland K, Stayner L. The importance of employment status in occupational cohort mortality studies. Epidemiolstatus in occupational $1991 ; 2 ; 418-23$.

14 Lison D, Carbonnelle P, Mollo L, et al. Physicochemical mechanism of the interaction between cobalt metal and carbide particles to generate toxic activated oxygen species. Chem Res Toxicol 1995;8:600-6.

15 Greenland S, Finkle WD. A critical look at methods for handling missing covariates in epidemiologic regression analyses. Am F Epidemiol 1995;142:1255-64. 